Iberian Journal of the History of Economic Thought

ISSN-e 2386-5768

\title{
Vicent Llombart Rosa (1948-2017): obituario. Historiografía y compilación bibliográfica
}

\section{Pablo Cervera Ferri ${ }^{1}$}

Resumen. El doctor Vicent Llombart Rosa fue catedrático de Historia del Pensamiento Económico de la Universitat de València y un reconocido experto en la Ilustración, miembro de la Real Academia de Ciencias Morales y Políticas, decano de la Facultad de Ciencias Económicas y Empresariales de Valencia y consejero del primer gobierno socialista valenciano de la democracia. A continuación se ofrecen su biografía, el resumen de sus principales aportaciones a la historiografía del siglo XVIII y una compilación de su obra académica y periodística.

Palabras clave: Vicent Llombart; biografía; historiografía; Ilustración.

[en] Vicent Llombart Rosa (1948-2017): obituary. Historiography and bibliographic compilation

Abstract. Dr. Vicent Llombart Rosa was Professor of History of Economic Thought at the University of Valencia and a renowned expert in the Enlightenment, member of the Royal Academy of Moral and Political Sciences, dean of the Faculty of Economics and Business of Valencia and counselor of the first socialist Valencian government on democracy. There are his biography, a briefing about his main contributions to $18^{\text {th }}$ century's historiography and a compilation of his academic and journalistic work.

Keywords: Vicent Llombart; biography; historiography; Enlightenment.

JEL Classification: B32

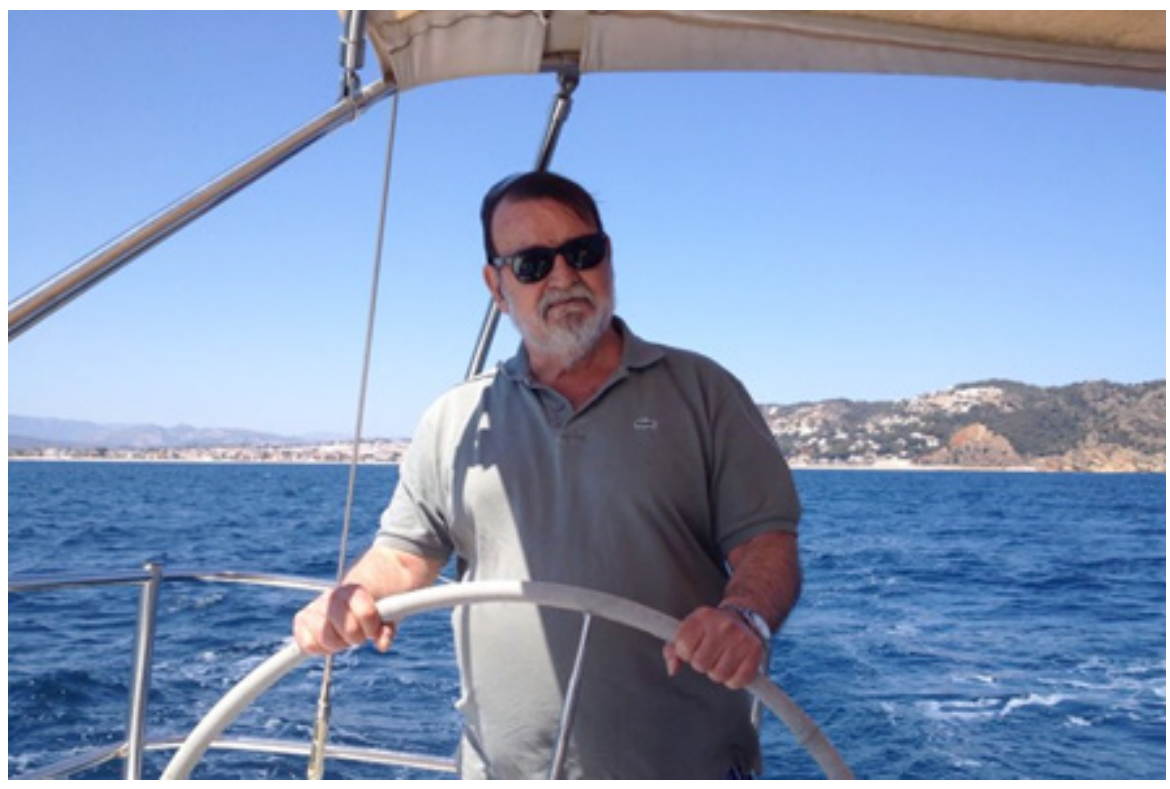

Universitat de València.

Pablo.Cervera@uv.es 
Su celo era cortés, al estar libre de toda muestra de amor propio; pero no por ello era menos entusiasta, porque el amor por el bien público era una pasión en M. Vincent. Estaba convencido de sus opiniones, sin obstinarse en ellas; su mente, siempre abierta, permanecía constantemente receptiva ante ideas nuevas e importantes, y nunca parecía que su posición previa retrasara lo más mínimo la súbita impresión que la verdad propuesta ejerce en un espíritu tan justo como el suyo.

A.R.J. Turgot: Éloge de Vincent de Gournay (1759)

\section{Inicios de la carrera académica y política de Vicent Llombart Rosa (1948-1979)}

Vicent Llombart trascendió en la vida política valenciana como el primer consejero (conseller) de Obras Públicas de un gobierno socialista. Su militancia en defensa de las libertades civiles y de la autonomía de su tierra natal se remonta a los últimos años del franquismo. No obstante, destacó ante todo como un extraordinario docente - fue en esta faceta como tuvo el privilegio de conocerle quien suscribe este obituario-, como apasionado dieciochista de prestigio internacional y como figura clave en la actual organización de la Facultad de Economía de la Universitat de València.

Hijo de Vicente y María Dolores, el tercero de cinco hermanos, nació en Valencia el 28 de mayo de 1948. Estudió en los Colegios del Pilar y de Jesuitas de la misma ciudad. Se matriculó desde el curso 1966-1967 en el Centro Universitario de Estudios Económicos, después Facultad de Ciencias Políticas, Económicas y Comerciales de la Universidad de Valencia, y formó parte de la primera promoción de esta institución. También superó el primer año de la carrera de Derecho (1968-1969), que dejó inacabada para completar sus estudios de economía mientras realizaba el servicio militar. En marzo de 1970, todavía en el cuarto curso, se incorporó a filas en el arma de Infantería. Se licenció en Ciencias Económicas el 22 de julio de 1972 en la Universidad de Valencia. Terminadas las milicias en 1973, pasó a la reserva como alférez de complemento (1974). De su tiempo como estudiante recordaba las clases de Historia Económica de España de Jordi Na- dal Oller; las conferencias de Luis Ángel Rojo, José Luis Sampedro, Fabián Estapé, Gonzalo Anes y Pedro Schwartz; y muy particularmente, las enseñanzas de Ernest Lluch i Martín en el quinto curso:

Fue la presencia del profesor Lluch, a través de su insistencia en que la economía debe ser comprendida en el interior de un proceso histórico — lo que en absoluto contradice la necesidad del rigor analítico-, a través de la toma de contacto con nuevas corrientes heterodoxas o no contempladas en los estudios y, en definitiva, a través de su ejemplo y estímulo intelectual, lo que me decidió por la Historia del Pensamiento Económico como especialización profesional frente a las alternativas que estaba también barajando de la Teoría o la Historia Económicas. (Llombart, "Exposición...", 22-XI-1997: 2).

El 1 de abril de 1972, dos meses antes de licenciarse, comenzó su carrera académica como profesor ayudante de la cátedra de Historia de las Doctrinas Económicas, adscrita al entonces Departamento de Teoría Económica de la recién rebautizada como Facultad de Ciencias Económicas y Empresariales. Dio su primera clase sobre Böhm-Bawerk e impartió en aquel curso las prácticas de Historia Económica de España (1972-1973). Comenzó a trabajar junto a Salvador Almenar Palau y Segundo Bru Parra en el seminario de la cátedra de Historia de las Doctrinas, dirigido por Ernest Lluch, sobre la "Evolución internacional de la literatura económica (1550-1848)". Allí descubrió la lectura directa de grandes economistas como Keynes, Schumpeter y Sraffa, y aprendió a identificar el potencial que ofrecía el pensamiento económico español como campo de investigación. Las primeras colaboraciones con su compañero Salvador Almenar datan de 1972: dos traducciones para uso interno de las obras sobre la fisiocracia de Michel Luftalla y de Marguerite Kuczynski con Ronald Meek, que basaron la publicación conjunta de sendas recensiones para Anales de Economía y Moneda y Crédito. También participó en el seminario de Historia Económica, donde asistió a los cursos impartidos por Emili Giralt, Joan Reglà, Màrius García Bonafé y, desde 1974, Josep Fontana.

El 1 de febrero de 1973 ganó la plaza de adjunto contratado en las cátedras de Historia 
de las Doctrinas y de Organización Económica Internacional de la Universidad de Valencia. Publicó poco después su primer artículo en Moneda y Crédito: unas "Anotaciones a la introducción del 'Ensayo sobre la población', de Malthus en España" en homenaje al entonces recién fallecido hispanista Robert S. Smith. Demostraba que dicha obra fue conocida antes de su primera traducción al castellano (1846). Tales notas marcarían el inicio de una línea de investigación acerca de la difusión de las ideas y de las historias nacionales del pensamiento económico. También ingresó en la Junta de Gobierno de la Real Sociedad Económica de Amigos del País de Valencia, antigua institución que se reactivaba con las iniciativas de Joaquín Maldonado Almenar, Manuel Sanchis Guarner y Francisca Aleixandre Tena.

Fue en aquel tiempo de agitación estudiantil cuando dio sus primeros pasos en la clandestinidad política de los recién formados "Grups d'Acció i Reflexió Socialista" (GARS) de Vicent Ventura i Beltran, Joan Josep Pérez Benlloch y Màrius García Bonafé, en el origen del Partit Socialista del País Valencià (PSPV). Ejercería como secretario de formación del partido hasta 1977. También visitó por vez primera Florencia, donde conoció a Piero Barucci, fundador de la revista Storia del Pensiero Economico (1972). Un último hecho trascendente en 1973 fue la donación de Rafael Gasset y Carmen Dorado, descendientes del primer conde de Campomanes, de su colección de escritos a la Fundación Universitaria Española (FUE). Según confesara Vicent Llombart en $1976:^{2}$

Mis primeras impresiones y balbuceos en relación con el tema [de tesis] pronto experimentaron una evolución decisiva al coincidir con el traslado, y la consiguiente reaparición pública, del archivo personal del Conde de Campomanes a la Fundación Universitaria Española. Ya la primera visita a la Fundación —en junio de 1973 y donde fui amablemente acogido - me hizo comprobar que los planteamientos iniciales debían ser revisados, al existir un más amplio $-\mathrm{y}$ prácticamente desconocido- camino por cubrir del que he intentado al menos recorrer una parte.

La nota manuscrita, de 2 folios a doble cara, está en posesión de la familia de Vicent Llombart.
Fue profesor ayudante de clases prácticas de Historia de las Doctrinas Económicas con dedicación exclusiva desde el 1 de octubre de 1973 e impartió la asignatura introductoria de Teoría Económica (1973-1975). En 1974 tradujo los textos de David Ricardo en la edición de Claudio Napoleoni. Obtuvo la interinidad como profesor adjunto al año siguiente y fue secretario, relator y ponente de la "Primera Reunión de Historiadores del Pensamiento Económico" en Madrid. Desde el 30 de septiembre de 1975 fue contratado para enseñar Teoría Macroeconómica.

Durante la preparación de su tesis (19731976) frecuentó regularmente el archivo de Campomanes de la FUE, merced a la hospitalidad del bibliotecario Jorge Cejudo López. La documentación que consultaba evidenciaba llamativas lagunas en la literatura entonces disponible sobre el XVIII español. Por entonces ya había descubierto el manuscrito de Campomanes con las "Reflexiones sobre el Comercio Español a Indias" (1762), que se creía la extraviada cuarta parte de un texto sobre la Hacienda Real (1759) y resultó ser una obra posterior, más prolija y trascendente. Su publicación, planificada desde 1974, tendría no obstante que esperar. Observó además que la biografía de Campomanes seguía muy incompleta para el periodo de 1758 a 1762, a pesar de los meritorios trabajos pioneros de Álvarez Requejo (1954). Constató la fragilidad de muchos tópicos historiográficos respecto al pensamiento económico y político de la Ilustración española, y cuestionó arraigados apriorismos, tales como la identificación de lo ilustrado con lo burgués o su contraposición al mercantilismo. Campomanes - afirmaba Llombart - no era un personaje relevante del entorno de Carlos III, sino el protagonista de la toma de decisiones de política económica de la Ilustración temprana, a un nivel solo comparable con Colbert en el Diecisiete francés o con Pombal en Portugal. La tesis, finalmente titulada "Pensamiento y teoría de la política económica del conde de Campomanes. Economía e ideología de la 'Ilustración oficial' en España (1760-1790)", fue dirigida por el doctor Lluch y presentada en tres volúmenes in folio mecanografiados. Ofrecía en la primera parte el retrato de un "Campomanes desconocido", anterior a su nombramiento como fiscal del Consejo de Castilla, con ideas propias del mercantilismo tardío - en su acepción smithiana - para un país relativamente atrasa- 
do. La segunda parte reconstruía el "mercantilismo agrarista" de Campomanes en la cúspide del poder (1762-1790): un programa de acción distante del industrialismo, también de la fisiocracia, que obstaculizaba la senda moderna del crecimiento. Se doctoró cum laude el 13 de julio de 1976. El tribunal lo componían los profesores Francisco Tomás y Valiente, Lluch, Fontana, Schwartz y el entonces decano de la Facultad de Ciencias Económicas y Empresariales de Valencia, Manuel Sánchez Ayuso. En el mes de octubre era nombrado profesor adjunto interino de Historia de las Doctrinas Económicas.

En 1977 recibió una beca de la FUE para continuar su exploración del Archivo de Campomanes. Fue profesor agregado interino de Teoría Económica (Macroeconomía) entre el curso 1977-1978, de Economía Política en la Facultad de Derecho (1978-1979) y profesor encargado de curso hasta el inicio de 19791980. Algunos resultados de la tesis quedaron plasmados en diversas publicaciones sobre el posicionamiento de Campomanes respecto a la Única Contribución (1976b), el proyecto de Ley Agraria (1976c), la explotación de las colonias americanas (1979a) y la constitución de las Sociedades Económicas de Amigos del País (1979b). En febrero de 1978 nació $\mathrm{Nu}-$ ria, fruto de su primer matrimonio con Celeste Juan Millet.

\section{Los años en Madrid y en el gobierno valenciano (1979-1985)}

Vicent Llombart fue nombrado profesor adjunto interino en la Universidad Complutense de Madrid. Durante cuatro cursos, del 1 de octubre de 1979 hasta el 30 de diciembre de 1983, impartió clases de Historia de las Doctrinas Económicas en la cátedra del profesor Pedro Schwartz. Tuvo allí como alumnos a Fernando Méndez Ibisate, Luis Perdices de Blas y Manuel Santos Redondo, hoy destacados profesores de esta disciplina en las universidades madrileñas. Participó en el curso de doctorado sobre "El concepto y método de la Economía Política en la Historia del Pensamiento Económico", que le motivó para familiarizarse con la obra de Karl Popper en particular y, más generalmente, con los aspectos teóricos de la circulación de las ideas y de la epistemología económica. También pronunció una conferencia sobre "El mercantilismo de Adam Smith" en el seminario sobre "doctrina y economía" del escocés en el Instituto Universitario de Economía de Mercado.

La estancia en la capital le facilitó el trabajo de archivo en la FUE, donde concluyó la transcripción de las inéditas "Reflexiones sobre el comercio español a Indias" y compuso su estudio preliminar. El original fue entregado al Instituto de Estudios Fiscales en 1982, aunque la edición se retrasó seis años debido al abultado plan de trabajo de aquella "primera época" de la colección de Clásicos del Pensamiento Económico Español. Continuó su investigación sobre las Sociedades Económicas, analizando sus paralelismos con las homólogas francesas (1981a), y dedicó el resto de su tiempo a preparar el concurso-oposición al Cuerpo de Adjuntos de Universidad, que ganó el 3 de noviembre de 1983.

Tras ejercer como subsecretario de Programación Económica de la Presidencia de la Generalitat Valenciana (1982-1983), regresó definitivamente de Madrid el 30 de junio de 1983 para ser nombrado conseller de Obras Públicas, Urbanismo y Transportes en el gabinete de Joan Lerma Blasco. El puesto abarcaba también las atribuciones sobre vivienda y medio ambiente. Fue responsable de incorporar al autogobierno valenciano la toma de decisiones en materia de infraestructuras. Tuvo que lidiar con algunos problemas de enjundia; uno de los más conflictivos fue el del abastecimiento de agua potable en Dènia, que requirió su mediación en la disputa entre los ayuntamientos de Iryda de Oliva y Pego. Permaneció en el cargo hasta julio de 1985. Llombart confesaba que aquella fue "una experiencia en la que creo haber aprendido bastante - aunque nunca lo suficiente - sobre la naturaleza humana y sobre los procesos de decisión política, algo siempre importante para un economista, como ya señalaron Keynes y Schumpeter" ("Exposición...", 22-XI-1997: 9-10).

Entre 1983 y 1991 fue también miembro del consejo asesor de la revista Debats, del Instituto Valenciano de Estudios Económicos $\mathrm{y}$ la editorial Alfons el Magnànim, $\mathrm{y}$ vocal del tribunal para la concesión de las becas de la Fundación "Lluís de Sant Àngel" de ayuda a la investigación histórica. Esta institución continuaba la labor de fomento del conocimiento iniciada por las entidades que financiaron el Centro Universitario de Estudios Económicos de Valencia desde 1966 hasta mediados de los ochenta, dando salida a las aportaciones de la 
Caja de Ahorros de Valencia al Patronato de la Facultad de Ciencias Económicas y Empresariales. Poco más tarde, Vicent Llombart detentaría el cargo de consejero general y secretario de la Comisión de Control de Bancaja (19861995).

\section{La reincorporación en la Universitat de València y la investigación sobre el conde de Campomanes (1985-1995)}

El 23 de enero de 1985 tomó posesión de la titularidad en el Área de Historia e Instituciones Económicas de la Universitat de València, con dedicación a tiempo completo desde el 24 de julio. Su docencia se centró en la Historia del Pensamiento Económico (Plan de Estudios de 1973) y, desde el curso 19931994, en disciplinas afines: "Historia de las ideas y los hechos económicos en España" y un curso de doctorado sobre "Controversias en economía política". También impartió en abril de 1988 un seminario en la Fundación para el Desarrollo del Cooperativismo y la Economía Social (Fundescoop) sobre microeconomía. Al término de su carrera docente, enseñaría una asignatura del Plan de 2000 de "Introducción a la Historia del Pensamiento Económico" y otra sobre "Pensamiento económico heterodoxo".

La publicación en 1988 de las Reflexiones sobre el Comercio Español a Indias de Campomanes coincidió con las celebraciones oficiales del bicentenario del fallecimiento de Carlos IIII. Tales actos ofrecieron la ocasión de retomar sus investigaciones de la segunda mitad de los setenta sobre las Sociedades Económicas (1988b, 1989b) y la Ley Agraria (1988c, 1989a).

En 1989 fue nombrado vicedecano de Biblioteca y Asuntos Internos de la Facultad de Ciencias Económicas, en el segundo equipo de Ángel Ortí Lahoz, y vocal del Consejo de Política Científica e Investigación de la Generalitat Valenciana ( $D O G V$ de 7 de junio), cargos que desempeñaría hasta 1992 y 1996 respectivamente. En aquel último año recibió la solicitud del profesor Enrique Fuentes Quintana de redactar una síntesis sobre el ideario de Campomanes para incorporarla a la iniciativa que, más adelante, se transformaría en la colección Economía y economistas españoles. Desde la perspectiva que ofrece el tiempo transcurrido, aquella circunstancia decidió la trayectoria de sus futuras investigaciones. Como él mismo reconociera,

El encargo, luego repetido para unas jornadas en La Granda sobre los economistas asturianos [1991c], me obligó a desenterrar un tema [de tesis] que había inhumado quizá precipitadamente. Tuve que revisar la bibliografía y actualizar planteamientos, realizar nuevas investigaciones, y ese fue el origen inmediato del libro Campomanes, economista y político de Carlos III [...] (Llombart, "Exposición...”, 22-XI-1997: 10-11).

El encargo fue decisivo en dos aspectos: primero, porque la puesta al día le llevó a familiarizarse con las novedades nacionales y extranjeras sobre Campomanes; y en segundo lugar, al requerir adentrarse en la obra del otro prohombre de la Ilustración asturiana, Gaspar Melchor de Jovellanos. Estos estímulos tuvieron dos respuestas inmediatas. Emprendió en 1990, como investigador principal, un proyecto del Ministerio de Educación y Ciencia sobre "Pensamiento económico y reforma ilustrada en el siglo XVIII" para ampliar su campo de estudio a las ideas económicas de Bernardo Ward, Francisco Craywinkel, Enrique Ramos, Jovellanos y Cabarrús, y para profundizar en proceso político del periodo 1760-1790. Completaban el cuadro investigador los profesores Vicent Ribes Iborra y Enric Mateu Tortosa. También participó, al año siguiente, en otro proyecto sobre el "Análisis comparativo de la evolución del pensamiento económico europeo (1750-1950)" promovido por el "Centre Alexandre Vandermonde pour l'Histoire de la Pensée Économique", en colaboración con historiadores de diversos países. Por otra parte, se inscribió en el Centro de Estudios del Siglo XVIII de la Universidad de Oviedo (1990) para acceder de primera mano a la literatura jovellanista, hecho que marcará el inicio de una gratificante relación intelectual y vital con Asturias, su tierra de adopción. Encontró su mejor apoyo para la etapa que comenzaba en Ana Mirabet, con quien contrajo segundas nupcias en octubre de aquel mismo año.

La bibliografía reciente sobre Campomanes le sorprendió: cuestionaba la paternidad del Discurso sobre el fomento de la industria popular e, indirectamente, su centralidad como figura clave de la Ilustración económica 
española. Los investigadores asturianos Inmaculada Urzainqui y Álvaro Ruiz de la Peña habían propuesto la hipótesis de que aquella obra fuese una ampliación del casi homónimo Discurso sobre el modo de fomentar la industria popular, un ensayo que Manuel Rubín de Celis había publicado en 1774 para prologar la traducción del Tratado del cáñamo de Marcandier. La idea fue divulgada por José Caso González y suscrita simplificadamente por Donald Street, quien relegó a Campomanes a la condición de plagiario. ${ }^{3}$ Llombart se embarcó en la controversia y descubrió otra edición del Discurso de Campomanes, sin la Real Orden ni la autorización del Consejo, que restablecía su autoría. La argumentación fue publicada en los Cuadernos de Investigación Histórica de la FUE (1990a) y poco después en History of Political Economy (1991a). La primera reacción del profesor Street fue vehemente, al haber leído tan solo la versión extractada de la argumentación de Llombart, enviada a $H O P E$ en marzo de 1990. No obstante, se retractó en una posterior reseña del libro Campomanes, el economista de Carlos III (1994), ${ }^{4}$ reconociendo con ejemplaridad académica la coherencia de las pruebas presentadas.

Aquel libro, publicado en Alianza Editorial con la mediación de Carlos Rodríguez Braun y prologado por Ernest Lluch, supuso la culminación de una minuciosa revisión de la tesis desde diciembre de 1990, con una bibliografía rigurosa y novedosas aportaciones documentales. Las conclusiones habían sido debatidas en el seminario de Historia Económica de la Facultad de Ciencias Económicas de Valencia (1990b). Llombart se distanciaba de sus planteamientos originales con aproximaciones a la obra de Campomanes desde la historia económica, política, jurídica y de la educación. La primera parte reconstruía la biografía del economista de Tineo. La segunda analizaba la aplicación de las ideas de Campomanes en la política económica carlostercerista, en paralelo con las experiencias europeas. La tercera explicaba la última etapa vital del autor: sus coincidencias argumentales con algunos aspectos de la obra de Adam Smith, su actitud ante la Revolución Francesa y su selección de lecturas. El epílogo ofrecía sugerentes contrastes entre el absolutismo ilustrado y el liberalis-

Street. D. (1986): "The authorship of Campomanes' Discurso sobre el fomento de la industria popular: a note". History of Political Economy (18:1), 655-660.

$4 \quad$ Ver (1994b), (8) mo. "Más Estado y más mercado", afirmaba, resumiría en una máxima el ideario del asturiano; la alternativa no es tal cuando la política económica trata de fomentar el desarrollo en un contexto de atraso. El libro contó con una veintena de recensiones en revistas nacionales e internacionales y fue elogiado por historiadores de las ideas de la talla de Franco Venturi o Pascal Bridel. El 28 de septiembre de 1993 quedó primer finalista del Premio Nacional de Historia.

El esfuerzo realizado en la composición de esta obra aportó valiosos resultados para el proyecto de investigación. En 1993 prologó la Idea de la Ley Agraria española de Manuel Sisternes y Feliú (1786), un tratadillo que conocía bien tras yuxtaponerlo al plan de reformas campomanesiano (1989a). También datan de entonces sus primeros trabajos de corte generalista sobre las ideas y los hechos económicos de la Ilustración española. La versión preliminar de su texto sobre "La política económica de Carlos III" fue también debatida en el Seminario de Historia Económica de la Facultad valenciana (1993c) y dio lugar a un artículo publicado en la Revista de Historia Económica (1994e). Llombart retomaba posiciones en la discusión sobre el papel desempeñado históricamente por el Estado en la economía. Rebatía las tesis dominantes sobre el periodo 1760-1790 — “fiscalista", "cosmética" y del "fracaso bienintencionado" - mediante una metodología de fines-medios. Analizaba a continuación la trama política de la reforma económica - los procesos de decisión y de ejecución- y valoraba sus implicaciones sobre el crecimiento económico.

En este mismo sentido, el capítulo que en adelante formaría parte del libro en homenaje al Dr. Fabià Estapé (1997b), maestro de Ernest Lluch, fue presentado en una ponencia previa en San Sebastián sobre las "Paradojas de la Ilustración" (1993k). Cuestionaba la biyectividad entre la ideología agrarista y la imposibilidad de un desarrollo industrial que favoreciese el crecimiento económico moderno. Apuntaba que:

Los inicios de la "Revolución industrial", que suelen situarse por la historiografía en la época ilustrada (al menos para el caso británico), no se vieron acompañados ni estimulados por cantos de sirena hacia la nueva industria, ni siquiera por cierto entusiasmo industrializador por 
parte de los pensadores europeos más destacados del momento. [...] Las esperanzas e ilusiones de alcanzar el progreso de la riqueza [...] reposaban más en el desarrollo de la agricultura, y en cierta medida en la expansión comercial, que en el propio crecimiento y renovación de la industria. [...] ¿Fue en sus orígenes la Economía Política, además de una "ciencia lúgubre" también una "ciencia miope"? (1997b, 63-64).

Tras presentar una visión conjunta del ideario económico de los economistas ilustrados españoles más influyentes, el profesor Llombart desmentía, en la línea apuntada por Albert Hirschman - a quien conoció en aquel mismo año- el aparente contraste entre la persistencia de una ideología agrarista y las reformas, más o menos veladas, encaminadas a la promoción industrial del último tercio del siglo XVIII español.

Por su parte, la relación con Oviedo se intensificaba a medida que Vicent Llombart se sumergía en la literatura jovellanista. En julio de 1993, de regreso de una estancia como profesor invitado en el "Istituto di Economia Politica A. Pesenti" de la Universidad de Pisa, recibió una beca del el Instituto de Estudios Fiscales para emprender el proyecto sobre "Jovellanos, el Informe sobre la Ley Agraria y la economía política ilustrada". Quien suscribe este obituario era ayudante de escuela universitaria desde aquel curso. Comencé mi tesis doctoral sobre el pensamiento económico de la Ilustración valenciana bajo la dirección del profesor Llombart y colaboré con él en la transcripción de una selección inicial de textos de Jovellanos. Los primeros resultados de esta línea de investigación datan de 1994, con una ponencia sobre la "Ilustración en tiempo de revolución (el reto de Jovellanos)", y ocuparán el núcleo de su obra tardía.

En octubre de 1993 ingresó en el equipo editorial de The European Journal of the History of Economic Thought, cuyo primer número apareció en octubre de $1993 .^{5} \mathrm{Su}$ primera aportación fue una meditada reseña a tres textos de Luis de Molina editados por el profesor Francisco Gómez Camacho (1981-1991). $\mathrm{Su}$ tratamiento ofrecía "una nueva lectura de la economía de la escolástica española" ale-

Es el número de EJHET (1:1) del mes de septiembre. jada del tópico "precursorista" que indaga las raíces del liberalismo en Salamanca y Coimbra, e introducía el enfoque escolástico de la incertidumbre como una clave para entender ulteriores desarrollos de las ideas económicas. Hemos localizado entre la documentación legada por el profesor Llombart un "Provisional Draft" mecanografiado, de 17 de abril de 1993, con correcciones y comentarios manuscritos de Marjorie Grice-Hutchinson. Este escrito avala un enriquecedor intercambio de pareceres con la gran hispanista que defendiera, frente a la tesis de Schumpeter, la existencia de una Escuela de pensamiento salmantina.

\section{El decanato en la Facultad de Ciencias Económicas y Empresariales de la Universitat de València (1995-1997)}

El doctor Llombart fue elegido decano el 17 de mayo de 1995, siendo Pedro Ruiz Torres rector de la Universitat de València y sucediendo a José Enrique Bigné Alcañiz en el cargo. Componían su equipo decanal los profesores Roberto Escuder Vallés, Dolores Forés Conchell, Cristina de Fuentes Barberá, Gregorio Labatut Serer y Clara Martínez Fuentes. Fue un mandato complicado, en un momento de cambio político, y la Facultad debía demostrar su calidad frente a la creciente competencia externa de los centros privados valencianos. La reciente implantación del Plan de Estudios de 1993, que multiplicó exponencialmente el número de grupos de estudiantes y las necesidades docentes, coincidió con el traslado de la Facultad y de la Escuela Universitaria de Estudios Empresariales al actual campus de Tarongers (curso 19961997) y con la finalización de la Biblioteca "Gregorio Mayans" de Ciencias Sociales. Además, había que tramitar tres nuevos títulos que ofrecería la facultad: una licenciatura en Sociología y dos segundos ciclos de Ciencias Actuariales y de Investigación de Mercados. Todo esto requirió un enorme esfuerzo logístico y de control presupuestario. Las recurrentes visitas del profesorado para resolver deficiencias puntuales de infraestructura en sus recién estrenados despachos eran tan insistentes que el nuevo decano, en un vano intento de aligerar su agenda, colocó en su puerta un cartel que rezaba: "Mañana día 10 de marzo es el último día para comunicar la distribución de los enchufes pertinentes. En 
caso contrario, se entenderá que solo necesitan los ya colocados". Permítase esta licencia de humor valenciano.

Vicent Llombart presidió también durante esta etapa el Patronato del Centro de Documentación Europea (CDE) de la Universitat de València, un organismo pionero en Europa, creado en 1982 por los antiguos decanos Vicente Montesinos Julve y Aurelio Martínez Esteve para reunir bases de datos y publicaciones de la Comisión Europea. El CDE había funcionado hasta 1993 solo con los medios de la Facultad de Ciencias Económicas y Empresariales. El Patronato se fundó en aquella fecha con la representación del Rectorado, el Consejo Social de la Universitat de València y la Dirección General de Relaciones Institucionales de Presidencia de la Generalitat Valenciana. El decano Llombart reforzó la dotación financiera y reubicó al Centro en el nuevo escenario.

En 1995 dirigió los actos del "Bicentenari de la publicació de 'L'Informe sobre la llei agraria' d'En Gaspar Melchor de Jovellanos" celebrados en la Universitat de València. Su impronta es evidente. Fue ocasión para discutir en el Seminario de Historia Económica "Una nueva mirada al Informe de Ley Agraria de Jovellanos doscientos años después" (1995d), artículo que fue aceptado en la Revista de Historia Económica (1995e), enmarcado en un nuevo proyecto del Ministerio de Cultura en el que el doctor Llombart figuraba como investigador principal: "Pensamiento económico, reforma política y difusión de los conocimientos en España (1760-1880)". El equipo investigador era en esta ocasión más amplio y contaba con Salvador Calatayud Giner, Enric Mateu y yo mismo; Jesús Astigarraga Goenaga se sumó en 1997. Un segundo trabajo sobre "El Informe de Ley Agraria y su autor, en la historia del pensamiento económico" fue redactado en 1996 para una obra coordinada por Ángel García Sanz y Jesús Sanz Fernández sobre las Reformas y politicas agrarias en la historia de España (1996c). Igualmente publicó, con ocasión del vigésimo quinto aniversario del Colegio de Economistas de Valencia, un breve estudio histórico sobre la historia de la Facultad de Ciencias Económicas y Empresariales de Valencia, que celebraba treinta años de actividad (1996a). Apenas contó con bibliografía sobre esta última cuestión, solo abordada hasta entonces por el profesor José Honrubia López, y hubo de realizar labor de archivo para componer algunas series históricas. En septiembre de aquel año promovió también una iniciativa para la colaboración de los departamentos de Análisis Económico y de Economía Aplicada de la Universitat de València con el doctorado en Economía de la Universidad de la Habana. El proyecto fue coordinado por Salvador Almenar y Agustín González Díaz. Su visita a la isla caribeña daría más adelante resultados académicos, con la publicación en la Revista Bimestre Cubana de varios artículos sobre las Sociedades Económicas y sobre la cátedra de Economía Política de la Habana, con la coautoría del profesor Astigarraga (1998a, 1998b).

El puesto decanal y la experiencia previa en el gobierno valenciano atrajeron la lógica atención de la prensa. Vicent Llombart publicó, al final del mandato, diversas columnas críticas sobre el Museo Valenciano de la Ilustración (MUVIM), de reciente y polémica creación, y respecto a las reformas pendientes en las cajas de ahorros y en la Universidad española. Renunció al decanato el 29 de abril de 1997 para preparar la oposición a cátedra. Le sustituyó en funciones el vicedecano Gregorio Labatut hasta las elecciones de 29 de mayo de 1997, fecha en que fue investido Juan José Renau Piqueras.

La labor académica de Vicent Llombart se centró durante el periodo decanal en dos ejes: una incipiente investigación sobre la circulación de las ideas de la Ilustración europea en España y la preparación de los textos que, más adelante, se integrarían en el volumen 3 de Economía y economistas españoles, obra de cuyo equipo de dirección pasó a formar parte. El artículo en The European Journal of the History of Economic Thought titulado "Market of ideas and reception of Physiocracy in Spain: some analytical and historical suggestions" (1995b) se gestó tras una ponencia en el congreso de París sobre la difusión internacional de la fisiocracia (1993j) y un documento de trabajo del seminario departamental (1995a). Basándose en el enfoque de George Stigler, concluía que la debilidad de la fisiocracia no solo fue razonable, compartida por otras naciones de Europa, sino también saludable por sus potenciales efectos contraproducentes para el desarrollo español. Respecto al segundo eje, publicó conmigo un capítulo sobre el pensamiento económico de la Ilustración valenciana (1996) e iniciamos la composición de un "Catálogo de la literatura económica española del siglo XVIII", más tarde publicado parcialmente online en la Cyber review of modern historiography (Cromohs) y en edición exenta 
(2004b, 2005b). La intención era disponer de una bibliografía completa sobre las traducciones de textos económicos al y del castellano, para utilizarla en la extensa introducción al volumen 3 de Economía y economistas españoles. Asimismo, preparó con Jesús Astigarraga un documento de trabajo sobre "las primeras 'antorchas de la economía"' (1997) que actualizaba sus anteriores investigaciones respecto a la génesis de las Sociedades Económicas de Amigos del País.

\section{Vicent Llombart, catedrático de Historia del Pensamiento Económico (1997-2017)}

El doctor Llombart ganó la cátedra de Historia del Pensamiento Económico el 13 de octubre de 1996 y tomó posesión el de 20 de diciembre (BOE de 13 de enero de 1997). Presentó en el segundo ejercicio la "Edición y estudio preliminar del Informe de Ley Agraria y otros escritos económicos de Gaspar Melchor de Jovellanos", investigación que venía planificando desde 1993. En los tres años que transcurrieron hasta la culminación de esta obra se mantuvo activo en la prensa y presentó algunos resultados parciales del proyecto en Cuadernos Aragoneses de Economía (1998b). El panorama general de la Ilustración para la obra de Fuentes Quintana fue perfilándose en una conferencia en la Universidad de La Habana, en otro documento de trabajo (1998a) y en su ponencia para la Primera Reunión de la Asociación Ibérica de Historia del Pensamiento Económico en la Universidad de Barcelona, a finales de 1999. Esta Asociación, a cuya actividad está vinculada la Revista Ibérica de Historia del Pensamiento Económico (IJHET), había nacido el 27 de febrero durante la Tercera Conferencia Anual de The European Society for the History of Economic Thought, celebrada en Valencia. La reunión fundacional tuvo lugar en el entresuelo de la sede de la Universidad Internacional Menéndez Pelayo y fue convocada por los doctores Schwartz, Lluch y José Luís Cardoso en representación de sus respectivos grupos de investigación. El año 1999 terminó con dos grandes noticias: la primera fue la nominación de Vicent Llombart como académico correspondiente de Ciencias Morales y Políticas. La segunda, más celebrada, fue el nacimiento de su hijo Vicente, que ha iniciado en este curso 2017-2018 sus estudios de Economía.
La Real Academia publicó en 2000 Gaspar Melchor de Jovellanos. Escritos económicos, en la colección de nueva época de Clásicos del Pensamiento Económico Español. El extenso estudio preliminar parte del conocido retrato de Jovellanos por Goya para ubicar al protagonista en el ocaso de la Ilustración. Presta especial atención al Informe de Ley Agraria: su génesis, su núcleo analítico, su programa de reformas, sus fuentes intelectuales y su fortuna en España y en Europa. Las relaciones con Smith y con los más notables economistas de la Ilustración son tratadas en el epílogo, con la intención de resaltar el pragmatismo del asturiano ante las actitudes doctrinarias y en sus propuestas reformistas. La edición incluye el Informe, dos apéndices y los diez principales escritos.

También data de 2000 el celebrado volumen de Economía y economistas españoles sobre la Ilustración, con cinco contribuciones del profesor Llombart: la introducción, sendos textos sobre Campomanes y Jovellanos, y dos coautorías con Cervera y Astigarraga respecto al pensamiento valenciano y las Sociedades Económicas. La introducción valoraba las principales ideas económicas producidas o importadas en España durante el proceso de emergencia de la economía política. Reconstruía el periodo en tres etapas generacionales: la herencia de Uztáriz (1730-1760), la generación de Campomanes (1760-1780) y las décadas de Jovellanos. La exposición se complementaba con un panorama territorial de la Ilustración, desde el enfoque de las historias nacionales del pensamiento, y con el análisis de las traducciones económicas.

El fructífero fin de milenio terminó, sin embargo, con la desgarradora noticia del asesinato de Ernest Lluch en Barcelona por la banda terrorista ETA. 2001 fue un año intenso, doloroso en la memoria. El profesor Llombart participó muy activamente en prensa y en numerosos actos de recuerdo, presentando ponencias que reafirmaban la vigencia de los valores y las ideas del maestro: aquel era el mejor homenaje que podía rendirse a un académico ejemplar. En adelante se integraría en el Patronato de la Fundació Ernest Lluch, presidiría su Secció Valenciana y persistiría en la labor de conservación y de difusión del legado magistral.

La relación con investigadores y amigos asturianos del Instituto Feijoo se estrechó desde inicios del siglo XXI, muy particularmente 
con Joaquín Ocampo, Dolores Mateos, Elena de Lorenzo, Álvaro Ruiz e Inmaculada Urzainqui. Tras la feliz conclusión de la publicación de las principales obras económicas de Jovellanos, Vicent Llombart había resuelto saldar su antigua deuda con Campomanes. Entre 2002 y 2004 presentó diversas ponencias en el Instituto y en la Facultad de Economía de Oviedo, un artículo (2002-2003) y varios capítulos de libro que revisaban sus aportaciones sobre el ideario del autor (2003a, 2004c). Por fin la editorial KRK ofreció en 2009 una elegante edición facsimilar de las Obras completas de Campomanes en siete tomos in quarto, con un estudio preliminar sobre el Fomento económico y promoción de empleo en el reinado de Carlos III.

En el ínterin, el profesor Llombart retomó sus investigaciones sobre las traducciones económicas en la España del siglo XVIII, que derivaron en un creciente interés por los mecanismos de circulación internacional de las ideas (2005-2006) y por la tesis lluchiana de una historia "nacional internacionalista" del pensamiento económico (2007a). El contraste entre las realidades nacionales y la universalidad del conocimiento le llevó a revisar desde una perspectiva más plural su comprensión de la Ilustración económica española, como queda atestiguado en la introducción y la conclusión de su artículo en Mediterráneo Económico (2006a) y en diversas conferencias impartidas en Formigal (2007c), Navia (2007d) y Santander (2008b). El replanteamiento del profesor Astigarraga sobre la influencia de la fisiocracia en España, así como su polémica con Vicent Llombart respecto a la alternativa de un texto de Juan Álvarez Guerra al proyecto de reformas de Jovellanos (2008-2009), se enmarcan en este contexto académico. Una última ramificación de estas investigaciones, sobre las diversas acepciones del concepto de la "felicidad pública", su imbricación en el ideario ilustrado y su relación con el desarrollo económico, quedó como proyecto inacabado $(2006,2016)$.
Las últimas aportaciones del doctor Llombart a la historiografía de la Ilustración española estuvieron motivadas por la oportunidad, de nuevo brindada por KRK, de presentar junto al profesor Ocampo la colección completa de Escritos económicos de Jovellanos (2008h), integrada en un ambicioso proyecto de edición de la obra literaria del asturiano en diecisiete tomos. Se centraron en su ideario tardío, desde los años convulsos de la Revolución francesa hasta 1808 . La enfermedad, que comenzó a minar la salud de Vicent Llombart desde 2008, y la jubilación voluntaria y anticipada en 2010 no mermaron su producción científica. $\mathrm{Su}$ ánimo mejoró tras el deseado nacimiento de Mar, su nieta, en diciembre de 2012. Puso especial cuidado en la elaboración de tres ensayos que habrían de constituir el armazón de su último libro, Jovellanos y el otoño de las luces (2013a). El primero revisaba críticamente la actual literatura jovellanista (2011f). El segundo (2012a) replanteaba la viabilidad del proyecto de reforma agraria de Jovellanos: se preguntaba si solo fue "un sueño dorado de la razón", con referencia al retrato de Goya que tanto le fascinaba, frustrado por los acontecimientos de fin de siglo. El último, que analizaba los paralelismos y las discrepancias entre los programas económicos de Jovellanos y de Campomanes, quedó pendiente de su definitiva edición.

A fecha de su fallecimiento, sobrevenido en Valencia el 29 de enero de 2017, Vicent Llombart permanecía en su cargo como subdirector de la revista IJHET y comenzaba una investigación sobre los aspectos morales de la obra de Adam Smith. Sus hijos, Nuria y Vicente, y su viuda Ana han donado generosamente su valiosa colección de obras de economía e historia de la ciencia a la Biblioteca universitaria "Gregorio Mayans" de Ciencias Sociales, a la que dedicara tantos esfuerzos siendo decano. La documentación personal y la obra literaria, en sus formatos informático y editado, quedan en propiedad de la familia. 


\section{Bibliografía (ordenada cronológicamente)}

Almenar, S. y Llombart, V. (1972a) "M. Luftalla. F. Quesnay: Tableau Économique des Physiocrates". Reseña. Anales de Economía (13), tercera época, enero-marzo, 238-241.

Almenar, S. y Llombart, V. (1972b) "M. Kuczynski y R. Meek (eds.). F. Quesnay: Quesnay’s Tableau Économique". Reseña. Moneda y Crédito (122), 209-213.

- (1973) “Anotaciones a la introducción del 'Ensayo sobre la población', de Malthus en España”. Moneda y Crédito (126), septiembre, 79-86. Existe separata.

Napoleoni, C. (1974) Fisiocracia, Smith, Ricardo, Marx. Traducción de V. Llombart y D. Bramón. Barcelona: Oikos-Tau.

Llombart, V. y Piñón, I. (1975-1976) "Sobre las relaciones entre coste y cantidad producida. Por Piero Sraffa". Traducción mecanografiada de V. Llombart de Sraffa, P. (1925): "Sulle relazioni fra costo e quantità prodotta", Annali di Economia (II), 277-328. Con nota introductoria de Salvador Almenar y Gabriel López Casares. Valencia: Copicrom. ISBN 84-600-1835-0; V-15.

Llombart, V. (1976a) "Pensamiento y teoría de la política económica del conde de Campomanes. Economía e ideología de la 'Ilustración oficial' en España (1760-1790)". Tesis doctoral. Valencia: Universidad de Valencia, Facultad de Ciencias Económicas y Empresariales. Dirigida por E. Lluch.

- (1976b) "A propósito de los intentos de reforma de la Hacienda castellana en el siglo XVIII: Campomanes frente al proyecto de Única Contribución”. Hacienda Pública Española (38), 123-132.

- (1976c) "Sobre los orígenes de los proyectos agrarios en la España de la segunda mitad del siglo XVIII. Ley Agraria y 'Sociedades de Agricultura'. La idea inicial de Campomanes". Información Comercial Española (512), abril, 57-74.

- (1976d) "Pensamiento y teoría de la política económica del conde de Campomanes". En Aracil, R. y García Bonafé, M.: Lecturas de historia económica de España. Siglos XVIII y XIX. Barcelona: OikosTau, 157-163.

Lluch, E., Almenar, S., Bru, S. y Llombart, V. (1977): "Elementi di bibliografia sulla storia del pensiero dello Stato Spagnolo". Ponencia. Verona: "IV Convegno Nazionali degli Storici del Pensiero Economico", marzo.

Llombart, V. (1977-1978a) "La Teoría General de la Ocupación. J.M. Keynes". Documento de trabajo. Valencia: Facultad de Ciencias Económicas y Empresariales de la Universidad de Valencia. Traducción mecanografiada de V. Llombart, 15 pp. in folio.

- (1977-1978b) "J.A. Kregel. El modelo básico. El sector de bienes de consumo y el sector de bienes de capital". Documento de trabajo. Valencia: Facultad de Ciencias Económicas y Empresariales de la Universidad de Valencia. Traducción mecanografiada de V. Llombart, $31 \mathrm{pp}$. in folio, de (1973): The Reconstruction of Political Economy: an Introduction to Post-Keynesian Economics. Macmillan, Edinbourgh.

- (1978a) "Ilustración española e independencia de América". Ponencia. Barcelona: "Coloquio sobre Ilustración española e independencia de América", Universidad Autónoma de Barcelona, 5-8 de abril.

- (1978b) “G. Mayans y Ciscar: escritos económicos”. Reseña. Investigaciones Económicas (6), 290-295.

- (1978c) "Mercantilismo tardío, 'liberalización comercial' y explotación colonial americana: Las Reflexiones de Campomanes". Ponencia. Bellaterra: Universidad Autónoma de Barcelona, Coloquio "Ilustración española e Independencia de América", 5-8 de abril.

- (1979a) "Mercantilismo tardío, 'liberalización comercial' y explotación colonial americana: Las Reflexiones sobre el comercio española Indias (1762) del Conde de Campomanes". En Gil Novales, A. (ed.): Homenaje a Noël Salomon. Ilustración española e independencia de América. Barcelona: Universidad Autónoma de Barcelona, 333-343. Es la edición de la comunicación presentada en el homenaje a Salomon en Bellaterra.

- (1979b) "Absolutismo e Ilustración: la génesis de las Sociedades Económicas de Amigos del País". Valencia: Publicaciones de la Real Sociedad Económica de Amigos del País de Valencia, Sección de Ciencias Sociales, 3-15. Existe Separata (como libro exento).

- (1981a) "El sorgiment de les Societats Econòmiques i llur conflicte amb les institucions comercials". Recerques: Història, economia i cultura (11), 181-198.

6 En octubre de 2010, MMC escaneó dicho opúsculo y ABC lo convirtió en un documento de texto apto para una revisión actualizada por Alfons Barceló (2010), publicada en Revista de Economía Crítica (10), segundo semestre, 219-264. 
- (1988a) Reflexiones sobre el comercio español a Indias. 1763. Edición, estudio preliminar y transcripción de Vicent Llombart. Madrid: Instituto de Estudios Fiscales y Ministerio de Hacienda, Clásicos del Pensamiento Económico Español. Reseña en (1989): Revista de Historia Económica (1), año VII, invierno, 223-227.

- (1988b) "Sociedades Económicas e Ilustración en el Reinado de Carlos III". En Actas de la Primera Asamblea de las Reales Sociedades Económicas de Amigos del país de las Islas Canarias. Santa Cruz de Tenerife y Las Palmas de Gran Canaria: Ministerio de Cultura, Comisión Nacional sobre Carlos III y la Ilustración, Litografía A. Romero, 193-205. Existe separata.

- (1988c) “Agricultura e Ilustración en España”. Ponencia. Segovia: Ministerio de Agricultura.

- (1988d) "Comparación entre los Ilustrados de la Corona de Aragón y los de Castilla y León sobre la Ley Agraria". Ponencia. Segovia: Ministerio de Agricultura y Comisión "Carlos III y la Ilustración (17881988)", Seminario sobre Agricultura e Ilustración en España, 14-16 de septiembre.

- (1989a) "Comparación entre los Ilustrados de la Corona de Aragón y los de Castilla y León. Campomanes, Sisternes y Asso ante la Ley Agraria". En Estructuras Agrarias y Reformismo Ilustrado en la España del Siglo XVIII. Actas del Seminario de Segovia sobre: Agricultura e Ilustración en España (14, 15 y 16 de septiembre de 1998). Madrid: Ministerio de Agricultura, Pesca y Alimentación. Secretaría General Técnica, 539-552.

- (1989b) "Sociedades Económicas e Ilustración en el Reinado de Carlos III. Ponencia presentada por la Real Sociedad Económica de Amigos del País de Valencia. Expuesta por D. Vicente Llombart Rosa, autor de la misma”. Anales 1987-1988 de la Real Sociedad Económica de Amigos del País de Valencia, mayo, 49-59, transcripción de la publicada en (1988) Santa Cruz de Tenerife y Las Palmas de Gran Canaria.

- (1989c) "El pensamiento económico de la Ilustración”. Ponencia. Benidorm: Universidad de Alicante, Cursos de verano, septiembre.

- (1990a) "El enigma de la paternidad del Discurso sobre el fomento de la industria popular. Campomanes rehabilitado". Cuadernos de Investigación Histórica (13), 283-303. Madrid: Fundación Universitaria Española, Seminario "Cisneros". Existe separata.

- (1990b) "Campomanes, el economista de Carlos III". Documento de trabajo. Valencia: Facultat de Ciències Econòmiques i Empresarials de la Universitat de València, Quaderns de Treball (171). Expuesto en el Seminario de Historia Económica del Departamento de Análisis Económico el 22 de abril.

- (1990c) "El mercantilismo de Adam Smith". Ponencia. Madrid: Seminario "Adam Smith: doctrina y economía", Universidad Complutense de Madrid, Instituto Universitario de Economía de Mercado, Facultad de Ciencias Económicas y Empresariales, Departamento de Historia e Instituciones I. 28 de noviembre.

- (1991a) "The Discurso sobre el modo de fomentar la industria popular and the Discurso sobre el fomento de la industria popular, Two Editions of the Same Work of Campomanes: A Reply to Donald Street". History of Political Economy (23:3), fall, 527-531. Durham: Duke University Press. Existe separata. Fue enviada en marzo de 1990.

- (1991b) "El libre comercio de granos (1765-1790). Pensamiento, política y efectos en el caso español". Ponencia. Zaragoza: Universidad de Zaragoza, "IV Jornadas sobre Historia del Pensamiento Económico", 6-7 de diciembre. 29 pp. in folio.

- (1991c) "Campomanes, un economista político liberalizador". Ponencia. La Granda (Avilés): Escuela Asturiana de Estudios Hispánicos, "Jornadas sobre Economistas Asturianos", La Caja de Ahorros de Asturias, agosto.

- (1992a) "La economía política de la Ilustración en España”. Ponencia. Valencia: Universitat de València, Facultad de Ciencias Económicas y Empresariales, Seminario de Historia Económica del Departamento de Análisis Económico, 2 de abril.

- (1992b) Campomanes, economista y político de Carlos III. Madrid: Alianza. Algunas reseñas (1993): (1) Bridel, P.: The European Journal of the History of Economic Thought (1:1), autumn, 189-191. London: Routledge. (2) Sánchez Hormigo, A.: The European Journal of the History of Economic Thought (21:1), autumn, 189-194. (3) History of Economic Ideas (1), 214-217 (4) Storia del Pensiero Economico (26), 83-88. (5) Revista de Economía Aplicada (2) 253-256. (6) Boletín de Estudios Económicos (148), abril, 202-203. (1993-1994): (7) Coronas, S.M.: Anuario de Historia del Derecho Español, t. LXIII-LXIV, 1333-1336. Madrid, s.i. (1994): (8) Street, D.: History of Political Economy (2) 194-199. (9) Noticiario 
de Historia Agraria (10) 155-176. Diversos suplementos literarios (ABC, Razón y Fe, Diario 16, Levante. El Mercantil Valenciano).

- (1992c) "Más mercado y más Estado. Máximas generales de la política ilustrada". Ponencia. Madrid: Universidad Complutense de Madrid, Instituto Universitario de Economía de Mercado, Facultad de Ciencias Económicas y Empresariales, Departamento de Historia e Instituciones I. 6 de mayo.

- (1992d) "Economia politica e politica económica nella Spagna di Carlos III. Ponencia. Pisa: Università degli Studi di Pisa, Dipartimento di Storia Moderna e Contemporanea", Seminario Permanente sulla Storia del Pensiero Economico Italiano tra Sei e Ottocento, Università degli Studi di Parma, 14 de junio.

- (1992e) "Grilletes feudales, futilidad y reforma económica posibilista en la España de Carlos III". Ponencia, Santander: "Encuentro con Albert Hirschman", UIMP, 23-24 de julio.

- (1992f) "Economía política, instituciones y gobierno en la España del siglo XVIII (1724-1812)". Ponencia. Zaragoza: Facultad de Economía, Departamento de Economía Política, 18 de noviembre.

- (1993a) "Albert O. Hirschman, un economista disidente". España Económica (3742), enero.

- (1993b) "Albert O. Hirschman, un economista disidente". Cambio-16 (1), 101.

- (1993c) "La política económica de Carlos III. ¿Fiscalismo, cosmética o estímulo al crecimiento?”. Documento de Trabajo. Valencia: Departamento de Análisis Económico de la Universitat de València, enero, 22 pp. in folio.

- (1993d) "La política económica de Carlos III. ¿Fiscalismo, cosmética o estímulo al crecimiento?”. Ponencia. Valencia: Universitat de València, Facultat de Ciències Econòmiques i Empresarials, Seminario de Historia Económica del Departamento de Análisis Económico, 26 de febrero.

— (1993e) "La política económica de Carlos III. ¿Fiscalismo, cosmética o estímulo al crecimiento?”. Ponencia. Madrid: Universidad Complutense de Madrid, Instituto Universitario de Economía de Mercado, Facultad de Ciencias Económicas y Empresariales, Departamento de Historia e Instituciones I. 3de mayo.

- (1993f) Idea de la Ley Agraria española. Barcelona: Alta Fulla, Clàssics del Pensament Econòmic Català, núm. 9. Reedición de 1786 con estudio preliminar de Vicent Llombart.

- (1993g) "La reforma económica de Carlos III (1760-1790): grilletes feudales, futilidad posibilismo". Claves de Razón Práctica (35), 62-63.

- (1993h) "John Locke por Victoriano Martín". Observaciones y comentarios". Ponencia. Ávila: Conference on "Monetary Controversies, Past and Present", Instituto Universitario de Economía de Mercado y London School of Economics, 12-14 de abril.

- (1993i) "A new Reading on Spanish Scholastic Economics of the Sixteenth Century". The European Journal of the History of Economic Thought (1:1), September, 194-199. Reseña de Luis de tres ediciones de Luis de Molina a cargo de Francisco Gómez Camacho: Tratado sobre los cambios (1991), Tratado sobre los préstamos y la usura (1989) y La Teoría del precio justo (1981).

- (1993j) "Utility, market for public ideas and reception of Physiocracy: suggestions from an Spanish perspective". Ponencia. En "La diffusion internationale de la Physiocratie", Paris, ENS Fontenay-St. Cloud, Centre Alexandre Vandermonde pour l'Histoire de la Pensée Économique, 23-24 de septiembre. Provisional Draft in May, 19 pp. in folio. Existe separata.

- (1993k) "Convicciones agraristas y actitudes industrialistas. Paradojas de la Ilustración (de Ward a Jovellanos". Ponencia. San Sebastián: V Congreso de la Asociación de Historia Económica, 29 de septiembre a 1 de octubre. $20 \mathrm{pp}$. in folio.

— (1994a) "Economic reform, Enlightenment and Inquisition in Spain: Pablo de Olavide (1725-1803)". Reseña de Perdices, L.: Pablo de Olavide (1725-1803), el ilustrado. Madrid: Ed. Complutense. The European Journal of the History of Economic Thought (1:2), spring, 420-425.

- (1994b) "El mercado de ideas de Stigler y la transmisión internacional de los conocimientos económicos: una aplicación al caso español”. Ponencia. Valencia: Universitat de València, Facultat de Ciències Econòmiques i Empresarials, Seminario de Historia Económica del Departamento de Análisis Económico, 13 de mayo.

- (1994c) "El mercado de ideas de Stigler y la transmisión internacional de los conocimientos económicos: una aplicación al caso español". Ponencia. Madrid: Universidad Complutense de Madrid, Instituto Universitario de Economía de Mercado, Facultad de Ciencias Económicas y Empresariales, Departamento de Historia e Instituciones I. 18 de mayo.

— (1994d) "Ilustración en tiempo de revolución (el reto de Jovellanos)". Ponencia. S.1. 7 de junio. 3 pp. in folio. 
- (1994e) "La política económica de Carlos III. ¿Fiscalismo, cosmética o estímulo al crecimiento?" Revista de Historia Económica (1), Año XII, invierno, 11-39.

- (1995a) "Mercado de ideas y recepción de la Fisiocracia en España: algunas sugerencias analíticas e históricas". Documento de trabajo. Valencia: Facultat de Ciències Econòmiques i Empresarials de la Universitat de València, Quaderns de Treball (3).

- (1995b) "Market of ideas and reception of Physiocracy in Spain: some analytical and historical suggestions". The European Journal of the History of Economic Thought (2:1), spring, 29-55. London: Routledge.

- (1995c) "Los economistas clásicos". Ponencia. Alicante: Universidad de Alicante, Facultad de Ciencias Económicas y Empresariales, Departamento de Historia Económica, Seminario de Doctorado, marzoabril.

- (1995d) "Una Nueva Mirada al Informe de Ley Agraria de Jovellanos Doscientos Años Después". Documento de Trabajo. Valencia: Departamento de Análisis Económico de la Universitat de València, DT 95-12. 33 pp. in folio.

- (1995e) "Una nueva mirada al Informe de Ley Agraria de Jovellanos doscientos años después". Revista de Historia Económica (3), año XIII, otoño, 553-580.

- (1995f) “¿La Ilustración en un museo?” Artículo de prensa. Levante. El Mercantil Valenciano, 7 de noviembre.

- (1995f) "Una ventana hacia Europa". Artículo de prensa. Levante. El Mercantil Valenciano.

— Llombart, V. y Cervera, P. (1996): “El pensamiento económico valenciano: una introducción histórica (1750-1850)". En Mateu, E., Azagra, J, y Vidal, J.: De la sociedad tradicional a la economía moderna. Estudios de Historia Valenciana Contemporánea. Alicante: Instituto de Cultura Juan Gil-Albert, Diputación Provincial de Alicante, 291-320.

- (1996a): "La Facultad de Ciencias Económicas y Empresariales (1966-1996) y la formación de los economistas valencianos". En VV.AA.: Colegio de Economistas de Valencia: 25 años de Economistas Valencianos. Valencia: COEV y PubliTrade, 106-115.

— (1996b) “Concepción de Castro: Campomanes. Estado y reformismo ilustrado. Madrid, Alianza, 1996”. Reseña. Revista de Economía Aplicada (IV: 10), 193-198. Zaragoza: Departamento de Economía Aplicada. Existe separata.

- (1996c) "El Informe de Ley Agraria y su autor, en la historia del pensamiento económico". En García Sanz, A. y Sanz Fernández, J. (coords.): Reformas y políticas agrarias en la historia de España (De la Ilustración al primer franquismo). Madrid: Ministerio de Agricultura, Pesca y Alimentación, Secretaría General Técnica, 105-159.

- (1997a) Screpanti, E. y Zamagni, S.: Panorama de historia del pensamiento económico. Barcelona: Ariel. Revisión técnica de S. Almenar, V. Llombart y P. Cervera.

- (1997b) "Convicciones agraristas y actitudes industrialistas. Paradojas de la ilustración (de Adam Smith a Jovellanos". En Lluch, E. y Costas, A.: Industrialización en España: entusiasmos, desencantos y rechazos. En Ensayos en Homenaje al profesor Fabián Estapé. Madrid: Civitas, Serie Especial, pp. 6183.

- (1997c) "Edición y estudio preliminar del Informe de Ley Agraria y otros escritos económicos de Gaspar Melchor de Jovellanos". Trabajo de investigación para la convocatoria pública de Cátedra de Universidad, resolución de 20 de diciembre de 1996 (BOE de 13 de enero de 1997). 402 pp. in folio.

Llombart, V. y Astigarraga, J. (1997): “Las primeras ‘antorchas de la economía': las Sociedades Económicas de Amigos del País en el siglo XVIII". Documento de trabajo. Valencia: Departamento de Análisis Económico de la Universitat de València, febrero.

Llombart, V. (1997d) "Reforma de las cajas: llamada a la prudencia". Artículo de prensa. Levante. EL Mercantil Valenciano, 25 de febrero.

- (1997e) "Bancaja: un legado de la Ilustración". Artículo de prensa. Levante. EL Mercantil Valenciano, 12 de marzo.

- (1997f) "Una reforma necesaria y viable de la Universitat de València". Artículo de prensa. El País. Comunidad Valenciana, 5 de mayo.

- (1997g) "El pensamiento económico de la Ilustración en España (1730-1812)". Ponencia. La Habana: Facultad de Economía de la Universidad de la Habana, seminario "Pensamiento económico cubano y español. Influencias, convergencias y divergencias", 15-19 de junio. 
Llombart, V. y Astigarraga, J. (1998a) “Las primeras 'antorchas de la economía': las Sociedades Económicas de Amigos del País en el siglo XVIII". Revista Bimestre Cubana, "De la Sociedad Económica de Amigos del País", vol. LXXXI (6), enero-junio, "De la Sociedad Económica de Amigos del País", vol. LXXXI,

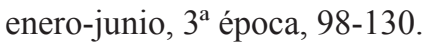

- y Astigarraga, J. (1998b) "La cátedra de Economía Política de la Habana (1818-1842) o el aprendizaje de la economía en el "Gran Libro del Mundo"'. Revista Bimestre Cubana, vol. LXXXIV (), juliodiciembre, $3^{\mathrm{a}}$ época, 81-99.

Llombart, V. (1997i) "Jovellanos y Adam Smith. Acerca del fenómeno de las influencias en la historia del pensamiento económico". Ponencia. Girona: VI Congreso de la Asociación de Historia Económica, 15-17 de septiembre.

- (1997j): "Exposición del primer ejercicio [de cátedra]". Documento particular mecanografiado con ocasión de su candidatura a la oposición de cátedra de Universidad, 30 pp. in folio. 22 de noviembre.

- (1997k) "Jovellanos, proteccionista". Zaragoza: Universidad de Zaragoza, V Jornadas sobre Historia del Pensamiento Económico, Homenaje al Profesor Fabián Estapé, 11-12 de diciembre.

- (1998a) “El Pensamiento Económico de la Ilustración en España (1730-1812)". Documento de trabajo. Valencia: Facultat de Ciències Econòmiques i Empresarials de la Universitat de València, Quaderns de Treball, 67.

- (1998b) "Jovellanos, proteccionista". Cuadernos Aragoneses de Economía (1), 41-51. Zaragoza: Facultad de Economía y Empresa de la Universidad de Zaragoza. Existe separata.

- (1998c) "Primarias y poder oligárquico". Artículo de prensa. El País. Comunidad Valenciana, 5 de mayo.

- y Almenar, S. (eds.) (1999): Third Annual Conference of the European Society for the History of Economic Thought. Book of Extended Summaries. Valencia: ESHET and UIMP.

- (1999a) "On the initial reception of Adam Smith in Spain". Ponencia. Valencia: Palacio de Pineda, III Annual Conference of the European Society for the History of Economic Thought, 26-27 de febrero. 4 folios mecanografiados.

- (1999b) "Los ilustrados ante el mundo rural: de Olavide a Jovellanos". Llanes: Universidad de Oviedo, Instituto Feijoo de Estudios del Siglo XVIII, curso sobre "Artes y Culturas Populares en la España del siglo XVIII", 12-16 de julio.

- (1999c) "El pensamiento económico de la Ilustración: un panorama sintético". Ponencia. Santander: UIMP, Encuentro sobre Economía y Economistas Españoles, 11-13 de agosto.

- y Almenar, S. (1999) "Spanish Societies, Academies and Associations of economic debate in the $19^{\text {th }}$ Century”. Ponencia. Pisa: Università di Pisa, Convegno Internazionale di Studi: La Società Degli economisti: una comparazione intenazionale: e L'Associazionismo economico nell'Italia dell'Ottocento, 14-16 de octubre.

Llombart, V. (1999d) “Pero, ¿qué es la Ilustración?”. Artículo de prensa. El País. Comunidad Valenciana, 31 de octubre.

- (1999e) "El progreso de los conocimientos económicos en un país científicamente atrasado: algunas sugerencias metodológicas". Ponencia. Barcelona: Universitat de Barcelona, Facultat de Ciències Econòmiques, $1^{\text {a }}$ Reunión de la Asociación Ibérica de Historia del Pensamiento Económico, 17-18 de diciembre.

- (2000a) "The progress of economic knowledge in one single and peripheral country: some suggestions from the $18^{\text {th }}$ century Spanish case". Ponencia. Graz: Fourth Annual Conference of the European Society for the History of Economic Thought, 24-27 de febrero.

- (2000b) Gaspar Melchor de Jovellanos. Escritos económicos. Estudio introductorio de Vicent Llombart. Madrid: Real Academia de Ciencias Morales y Políticas, Ministerio de Economía y Hacienda, Instituto de Estudios Fiscales, Fundación ICO, Clásicos del Pensamiento Económico Español, nueva época. Prólogo de Enrique Fuentes Quintana.

- (2000c) "Introducción. El pensamiento económico de la Ilustración en España (1730-1812)". En Fuentes Quintana, E. (Ed.): Economía y economistas españoles. Madrid: Galaxia Gütenberg-Círculo de Lectores, vol. III, 7-89.

- (2000d) "Campomanes, el economista de Carlos III". En Fuentes Quintana, E. (Ed.): Economía y economistas españoles. Madrid: Galaxia Gütenberg-Círculo de Lectores, vol. III, 201-255. 
- (2000e) "El Informe sobre la Ley Agraria de Jovellanos: núcleo analítico, programa de reformas y fuentes intelectuales". En Fuentes Quintana, E. (Ed.): Economía y economistas españoles. Madrid: Galaxia Gütenberg-Círculo de Lectores, vol. III, 421-445.

- y Cervera, P. (2000) "Economistas valencianos de la Ilustración (1760-1800)". En Fuentes Quintana, E. (Ed.): Economía y economistas españoles. Madrid: Galaxia Gütenberg-Círculo de Lectores, vol. III, 613-639.

- y Astigarraga, J. (2000) “Las primeras 'antorchas de la economía'; las sociedades económicas de amigos del país en el siglo XVIII”. En Fuentes Quintana, E. (Ed.): Economía y economistas españoles. Madrid: Galaxia Gütenberg-Círculo de Lectores, vol. III, 677-707.

Llombart, V. (2001a) "Spanish societies, academies and economic debating societies". En Augello, M. y Guidi, M.E.L.: The Spread of Political Economy and the Professionalisation of Economists. Economic Societies in Europe, America and Japan in the Nineteenth Century. London and New York: Routledge, $109-125$.

- (2001b) "La política económica de Carlos III: fundamentos doctrinales y realizaciones". Ponencia. San Sebastián: Universidad del País Vasco, Cursos de verano, Seminario Ernest Lluch, Ilustración y economía en España: proyectos y realidades, 26-27 de junio.

- (2001c) "Pensamiento y reformas económicas durante el siglo XVIII: balance y perspectivas". Ponencia. Santander: UIMP, Encuentro sobre Historia del pensamiento económico en España: balance y perspectivas (Homenaje a Ernest Lluch), 3-4 de septiembre.

- (2001d) "La Hacienda pública y los economistas españoles del siglo XVIII. De Uztáriz a Arriquíbar". Ponencia. Zaragoza: Universidad de Zaragoza, VII Congreso de la Asociación de Historia Económica, 19-21 de septiembre.

- (2001e) "Hace un año ya". Artículo de prensa. El País. Comunidad Valenciana, 21 de noviembre.

- (2001f) "Adéu Ernest". Artículo de prensa. El País. Comunidad Valenciana, 29 de noviembre.

- (2001g) "In memoriam. Ernest Lluch, un singular hombre de las Luces". Cuadernos de Estudios del Siglo XVIII (8-9), 227-248.

- (2001h) "Frente al dogmatismo del laissez-faire: Jovellanos y el comercio de granos". Ponencia. Porto: Universidade do Porto, Facultade de Economia, Segondo Encontro da Associação Ibérica de Historia do Pensamento Económico, 14-15 de diciembre.

— (s.f. [h. 2001]) "Ernest Lluch: la palabra, el reloj y la vía valenciana". Mecanografiado, 3 pp. in folio.

- (2002a) "Campomanes y Jovellanos, economistas ilustrados". Ponencia. Oviedo: Facultad de Ciencias Económicas.

- (2002b) "Informe sobre el pensamiento económico". Ponencia: Congreso Internacional Orígenes del liberalismo. Universidad, Política, Economía. Salamanca: Universidad de Salamanca, 1-4 de octubre.

- (2002-2003) “Campomanes en su tiempo y en el nuestro". Cuadernos de Estudios del Siglo XVIII (12 y 13), 47-91.

- (2003a) “Campomanes, ¿economista a la moda del tiempo?” En Mateos Dorado, D. (ed.): Campomanes doscientos años después. Oviedo: Publicaciones de la Universidad de Oviedo, Instituto Feijoo de Estudios del Siglo XVIII, 455-485.

- (2003b) "Pensamiento económico". En Robledo Hernández, R., Castells Oliván, I. y Romeo Mateo, M.C. (coords.): Orígenes del liberalismo: universidad, política, economía. Salamanca: Actas del Congreso Internacional "Orígenes del Liberalismo: Universidad, Política, Economía", 371-376.

- (2003c) "Campomanes ilustrado. Economía, política y reforma en tiempos de Carlos III". Ponencia. Jaén: Curso de Verano de la Universidad de Jaén: "Campomanes y Olavide: nuevas perspectivas y debates", La Carolina, Palacio del Intendente Olavide, 14-15 de julio.

- (2003d) "Nuevo catálogo de traducciones de economía política al y del castellano (1700-1812)". Ponencia. Granada: Tercer Encuentro de la Asociación Ibérica de Historia del Pensamiento Económico, Facultad de CC. Económicas y Empresariales, Universidad de Granada - CentrA, 1213 diciembre.

Llombart, V. (2003) "Prólogo de Vicent Llombart" En Cervera Ferri, P. El pensamiento económico de la Ilustración valenciana.. Valencia: Generalitat Valenciana, Conselleria de Cultura, Educació i Ciència. Biblioteca Valenciana.

Almenar, S. y Llombart, V. (2004): "Money, Prices and Empire. Monetary Ideas on Spanish Decadence in 16-1 $7^{\text {th }}$ Centuries". Treviso/Venezia: VIII Annual Conference of ESHET, Universitá Ca'Foscari, 26-29 febrero. 
Llombart, V. (2004a) "Campomanes y la Ilustración". Conferencia. Oviedo: Universidad de Oviedo e Instituto Feijoo de Estudios del Siglo XVIII, Facultad de Humanidades. 3 de marzo. 10 pp. in folio (esquemas).

- (2004b) “Traducciones españolas de economía política (1700-1812): catálogo bibliográfico y una nueva perspectiva". Cyber Review of Modern Historiography [Cromohs] (9), 1-14. Firenze: Firenze University Press, URL: http://www.cromohs.unifi.it/9_2004/llombart.html.

- (2004c) "Pensamiento económico y acción política de Campomanes". En Comín, F. y Martín Aceña, P.: Campomanes y su obra económica. Madrid: Ministerio de Economía y Hacienda e Instituto de Estudios Fiscales, 33-62.

- (2004d) "Turgot-Smith theorem". En Segura, J. y Rodríguez Braun, C. (eds.): An Eponymous Dictionary of Economics. A Guide to Laws and Theorems Named in Economists. Cheltenham (UK) and Northampton (USA): Edwar Elgar, 262-263.

- (2005a) “¿Son las ideas de los economistas más poderosas de lo que comúnmente se cree?” [Solo le idee degli economisti più poderose di quello che comunemente si crede?] Ponencia. Lucca: III Summer School in Storia del Pensiero Economico. Università di Firenze e Pisa. 5-8 de septiembre. 15 pp. in folio.

- (2005b) Traducciones españolas de economía política (1700-1812): catálogo bibliográfico y una nueva perspectiva. Valencia: Reproexpress. Autoedición, 80 pp. in quarto. Edición exenta de la versión en web de Cromohs.

- (2006a) "Economía política y reforma en la Europa mediterránea del siglo XVIII: una perspectiva española". Mediterráneo Económico (9), 95-113.

- (2006b) "Ernest Lluch en su último tramo". Artículo de prensa. El País. Comunidad Valenciana, 18 de enero.

- (2006c) "Los Borbones y las Luces". Artículo de prensa. El País. Comunidad Valenciana, 3 de febrero.

- (2006d) "Realitat nacional, ciència universal i pensament econòmic: 26 anys després". Ponencia. Barcelona: Universitat de Barcelona, Facultat de Ciències Econòmiques, III Seminari Ernest Lluch, 20 de febrero. $5 \mathrm{pp}$. in folio [Son esquemas]

- (2006e) "Patrimonio valenciano y bronca cultural”. Artículo de prensa. El País. Comunidad Valenciana, 22 de febrero.

- (2006f) "Illuminismo, sviluppo económico e felicità umana". Ponencia. Lecce: Università di Lecce, Corso di Laurea interfacoltà in Scienze Sociali: Cooperazione Internazionale, Sviluppo e Non-profit, 16 de marzo. 7 pp. in folio.

Llombart, V. y Almenar, S. (2006): “La Nueva Economía Política de John Stuart Mill”. Valencia: Universitat de València, Seminario "Derechos en conflicto. Reflexiones desde el Derecho, la Política y la Economía a partir del pensamiento de John Stuart Mill", 4 de mayo. 6 pp. in folio.

Llombart, V. (2006g) “Realidad nacional y circulación internacional del pensamiento económico". Ponencia. Versión castellana revisada de la ponencia de 20 de febrero de 2006, de 25 de agosto, 25 pp in folio.

— (2006h) “Traspassar fronteres, traduir les Llums. Economia i traducció a l'Espanya del segle XVIII”. En Miscel-lània. Homenatge a Ernest Lluch, vol. I, 119-134. Vilassar de Mar: Fundació Ernest Lluch.

- (2006i) "Leer y entender a Adam Smith: a modo de réplica a Victoriano Martín". Libros de Economía y Empresa (2), 23-24.

- (2007a) "Ernest Lluch e la storia 'nazionale internzionalista' del pensiero económico". Lucca: Università di Pisa e Università di Firenze, 5th International Summer School AISPE, 5-8 de septiembre. 16 pp. in folio.

- (2007b) "Ernest Lluch, Economista de amplia mirada (Un primer inventario de su obra)". Libros de Economía y Empresa (2), 43-44.

- (2007c) "La Economía política en España (1760-1812): ideas, recepciones e instituciones". Ponencia. Formigal: Seminario "Estado absolutista, Estado constitucional. Economía y política en la construcción de la España moderna", UIMP-Universidad de Zaragoza, 17-19 de septiembre.

- (2007d) "El legado de la Ilustración económica española". Navia: Curso de Extensión Universitaria.

- (2008a) "Pedro Rodríguez Campomanes, conde de Campomanes"; "Baltasar Gaspar Melchor de Jovellanos"; "Ramón Campos". En: Perdices de Blas, L. y Sánchez Hormigo, A. (coords.): 500 años de economía a través de los libros españoles y portugueses - 500 years of economic writing in Spanish and Portuguese. Madrid: Universidad Complutense, Biblioteca Histórica Marqués de Valdecilla. 
- (2008b) "El pensamiento económico de la Ilustración española: nueva mirada, nuevas aportaciones". Ponencia. Santander: I Seminario Ernest Lluch: "Homenaje al profesor Enrique Fuentes Quintana", Fundació Ernest Lluch, ICO, UIMP, 18 de julio.

- (2008c) "Jovellanos, Godoy y la Ilustración tardía. Reforma económica y convulsión política en España (1789-1808)". Ponencia. Navia: Curso de Extensión Universitaria: "1808, ¿frontera histórica?"

- (2008d) "La supuesta alternativa fisiócrata de Juan Álvarez Guerra al Informe de Ley Agraria de Jovellanos. Una reconsideración". Revista de Historia Económica / Journal of Iberian and Latin American Economic History (3), año XXVI, invierno, 441-488.

- (2008e) "Leer los textos". Revista de Historia Económica / Journal of Iberian and Latin American Economic History (3), Año XXVI, invierno, 499.

- (2008f) "Economía e Ilustración en tiempos de Revolución: el reto de Jovellanos". Ponencia. Oviedo y Gijón: Universidad de Oviedo e Instituto Feijoo del siglo XVIII, IV Congreso Internacional de la Sociedad Española de Estudios del Siglo XVIII, 15-17 de octubre.

- (2008g) "Una monarquía ilustrada en tiempos de Revolución: la alternativa de Jovellanos (17881808)". En De Lorenzo Álvarez, E. (coord.): La época de Carlos III (1788-1808). Oviedo: Actas del IV Congreso Internacional de la Sociedad Española de Estudios del Siglo XVIII, 707-718.

- (2008h) Gaspar Melchor de Jovellanos. Obras Completas. Tomo X Escritos Económicos. Edición crítica, estudio preliminar, prólogo y notas de Vicente Llombart i Rosa y Joaquín Ocampo SuárezValdés. Gijón: Ayuntamiento de Gijón, Instituto Feijoo de Estudios del siglo XVIII, KRK Ed.

— (s.f. [h. 2008]) "Jovellanos: luces de atraso y progreso". Ponencia. 5 pp. in folio.

- (2009a) Rodríguez Campomanes, P.: Obras completas. Vol. I: Fomento económico y promoción de empleo en el reinado de Carlos III. (Estudio preliminar a las Obras completas de Vicent Llombart). Vol. II: Discurso sobre el fomento de la industria popular (1774). Vol. III: Discurso sobre la educación popular de los artesanos y su fomento (1995). Vols. IV-VII: Apéndices a la educación popular (17751777). Oviedo: Instituto Feijoo de Estudios del Siglo XVIII, KRK Ed.

- (2009b) "El valor de la Fisiocracia en su propio tiempo: un análisis crítico". Investigaciones de Historia Económica (15), otoño, 109-136.

- (2009c) “La fisiocracia: ¿otro claroscuro de la Ilustración?”. En Astigarraga Goenaga, J., López-Cordón Cortezo, M.V. y Urquía Echave, J.M. (coords.): Ilustración, ilustraciones, vol. 2, 531-546.

- (2009d) "Economía, Traducciones de". En Lafarga, F. y Pegenaute, L. (coords.): Diccionario histórico de la traducción en España, Madrid: Gredos, 325-334.

- (2010) "Una aproximación histórica y analítica al pensamiento económico de Jovellanos". Madrid: Documentos de trabajo de la Asociación Española de Historia Económica (12).

- (2011a) "Jovellanos y Campomanes: sintonías y contrastes". Ponencia. Gijón: Universidad de Oviedo e Instituto Feijoo de Estudios del Siglo XVIII, 4-6 de mayo.

- (2011b) "El reto de Jovellanos, ilustración en tiempos de revolución". Artículo de prensa. La Voz de Asturias, 8 de mayo.

— (2011c) "Ni teoría sin aplicación, ni aplicación sin teoría: economía política y realismo en Jovellanos". Ponencia. VI Encuentro de la Asociación Ibérica de Historia del Pensamiento Económico. Zaragoza: Universidad de Zaragoza, 1-3 de diciembre. 25 pp. in folio.

- (2011d) "Luces, sueños y amarguras de Jovellanos". Conferencia. Madrid: Museo de la Biblioteca Nacional. 14 de diciembre.

- (2011e) Tres ensayos sobre Jovellanos (Colección de textos no definitivos). Valencia: Reproexpress. Autoedición. Incluye: (1) "El pensamiento económico de Jovellanos y sus intérpretes"; (2) "La reforma agraria de Jovellanos: ¿un sueño dorado de la razón?”; (3) Jovellanos y Campomanes: sintonías y contrastes".

- (2011f) "El pensamiento económico de Jovellanos y sus intérpretes". En Ignacio Fernández Sarasola, Elena de Lorenzo Álvarez, Joaquín Ocampo Suárez-Valdés, Álvaro Ruiz de la Peña Solar (eds.): Jovellanos, el valor de la razón (1811-2011) 75-103. Gijón: Trea. [Es el texto definitivo del autoeditado en Tres ensayos sobre Jovellanos (2011)].

- (2012a) "La reforma agraria de Jovellanos: ¿un sueño dorado de la razón?” En Fernández Sarasola, I; De Lorenzo Álvarez, E.; Ocampo Suárez-Valdés, J. y Ruiz de la Peña Solar, A. (coords.): Jovellanos: el hombre que soñó España. Presentación de J.L. Martínez. Madrid: Ateneo Jovellanos, Fundación Ateneísta de Asturias y Eds. Encuentro S.A., 169-195. [Es el texto definitivo del autoeditado en Tres ensayos sobre Jovellanos (2011)]. 
- (2012b) "Pensamiento económico e Ilustración en España (1724-1812): un panorama". Ponencia (esquemas). Valencia: Facultat d'Economia de la Universitat de València, Seminario de Pensamiento Económico Contemporáneo, curso 2011-2012, 29 de febrero.

- (2012c) “Jovellanos, ante Cádiz”. Artículo de prensa. El Heraldo de Aragón, 18 de marzo núm. 471, 14.

-- y Ocampo Suárez-Valdés, J. (2012): "Para leer el Informe de Ley Agraria de Jovellanos". Revista Asturiana de Economía (45), primer semestre, 119-143. Monográfico sobre "Jovellanos, economista"

Llombart, V. (2012d) "Ni teoría sin aplicación, ni aplicación sin teoría: economía política y realismo en Jovellanos". Revista Asturiana de Economía (45), primer semestre, 7-31. Monográfico sobre "Jovellanos, economista".

- (2013a) Jovellanos y el otoño de las Luces. Educación, economía, política y felicidad. Gijón: Trea. Existe reseña de Juan Velarde Fuertes (2013): “Jovellanos, economista actual”. En El Economista, 31 de agosto.

- (2013b) "Palabras de presentación del libro: Jovellanos y el otoño de las Luces. Educación, economía, política y felicidad. Editorial Trea". Ponencia. Gijón: Centro de Cultura Antiguo Instituto de Gijón, 27 de mayo.

- (2013c) "Jovellanos y la reforma agraria. Progreso en condiciones de atraso". Ponencia. La Granda (Avilés): 7 de agosto, 23 pp.

- (2013d) "Perspectiva económica de Goya". Ponencia. S.1. 9 de octubre. 29 pp. in folio.

- (2013e) "Adam Smith: moral, riqueza y libertad económica moderada". Conferencia. Zaragoza: Universidad Internacional Menéndez y Pelayo y Facultad de Economía de la Universidad de Zaragoza, Seminario "Libertad, mercado y Estado. Debates en el pensamiento económico". 24-25 de octubre. 8 pp. in folio (versión Word). Hay una segunda versión en diapositivas pptx (10 pp.).

- (2014a) "Perspectivas económicas de Goya". Estudios de Economía Aplicada (32:1), 111-138.

- (2014b) "Los intensos años valencianos de Ernest Lluch". En: Maestros de ciudadanía: Manuel Broseta, Ernest Lluch, Francisco Tomás y Valiente. Valencia: Universitat de València, 95-103.

- (2016a) "Felicidad pública". Ponencia. Navia: Curso de Extensión Universitaria: Ilustración y felicidad pública.

- (2016b) Proyecto de libro con J. Ocampo: "De Uztáriz a Jovellanos: Economía, política e Ilustración en España, 1724-1812”. Hay índice y esquema inicial, mecanografiados.

\section{Proyectos y becas de investigación:}

Llombart, V. (1990-1994) "Pensamiento económico y reforma ilustrada en el siglo XVIII". Investigador principal. Equipo investigador: Vicent Ribes Iborra y Enric Mateu Tortosa. Ministerio de Educación y Ciencia, Subdirección General de Promoción a la Investigación, PB90-0576. 2.550.000 ptas.

- (1993) "Jovellanos, el Informe sobre la Ley Agraria y la economía política ilustrada". Beca de investigación. Ministerio de Economía y Hacienda, Instituto de Estudios Fiscales. 500.000 ptas.

- (1995-1998) "Pensamiento económico, reforma política y difusión de los conocimientos en España (1760-1880)". Investigador principal. Equipo investigador: Jesús Astigarraga Goenaga, Salvador Calatayud Giner, Pablo Cervera Ferri, Enric Mateu Tortosa. Ministerio de Educación y Cultura. Secretaría de Estado de Universidades Investigación y Desarrollo. Dirección General de Enseñanza Superior e Investigación Científica y Técnica (DGICYT), PS94-0182. 3.320.000 ptas. 